\title{
Identification of a Dopamine Receptor-Mediated Opiate Reward Memory Switch in the Basolateral Amygdala-Nucleus Accumbens Circuit
}

\author{
Alessandra Lintas, ${ }^{\star}$ Ning Chi, ${ }^{\star}$ Nicole M. Lauzon, Stephanie F. Bishop, Shervin Gholizadeh, Ninglei Sun, Huibing Tan, \\ and Steven R. Laviolette \\ Department of Anatomy \& Cell Biology, Schulich School of Medicine and Dentistry, University of Western Ontario, London, Ontario N6A 5C1, Canada
}

\begin{abstract}
The basolateral amygdala (BLA), ventral tegmental area (VTA), and nucleus accumbens (NAc) play central roles in the processing of opiate-related associative reward learning and memory. The BLA receives innervation from dopaminergic fibers originating in the VTA, and both dopamine (DA) D1 and D2 receptors are expressed in this region. Using a combination of in vivo single-unit extracellular recording in the NAc combined with behavioral pharmacology studies, we have identified a double dissociation in the functional roles of DA D1 versus D2 receptor transmission in the BLA, which depends on opiate exposure state; thus, in previously opiate-naive rats, blockade of intra-BLA D1, but not D2, receptor transmission blocked the acquisition of associative opiate reward memory, measured in an unbiased conditioned place preference procedure. In direct contrast, in rats made opiate dependent and conditioned in a state of withdrawal, intra-BLA D2, but not D1, receptor blockade blocked opiate reward encoding. This functional switch was dependent on cAMP signaling as comodulation of intra-BLA cAMP levels reversed or replicated the functional effects of intra-BLA D1 or D2 transmission during opiate reward processing. Single-unit in vivo extracellular recordings performed in neurons of the NAc confirmed an opiate-statedependent role for BLA D1/D2 transmission in NAc neuronal response patterns to morphine. Our results characterize and identify a novel opiate addiction switching mechanism directly in the BLA that can control the processing of opiate reward information as a direct function of opiate exposure state via D1 or D2 receptor signaling substrates.
\end{abstract}

\section{Introduction}

Opiate-related memory cues trigger drug seeking and craving and are a primary factor in opiate addiction relapse. The ventral tegmental area (VTA), nucleus accumbens (NAc), and basolateral nucleus of the amygdala (BLA) form a functionally interconnected network that is critical for processing the primary rewarding effects of opiates as well as opiate-related memory. Thus, opiates act within the mesolimbic pathway to produce rewarding effects via DA-independent or DA-dependent pathways, depending on opiate exposure state (Nader and van der Kooy, 1997; Laviolette et al., 2002, 2004). Beyond the VTA $\rightarrow$ NAc pathway, the BLA receives DAergic projections from the VTA, which modulate amygdalar associative neuronal plasticity (Bissière et al., 2003). Anatomical evidence demonstrates that opiates act on VTA $\mu$ receptors, which indirectly activate DAergic neurons projecting to the BLA (Ford et al., 2006). However, the significance of

Received April 8, 2011; revised May 25, 2011; accepted June 9, 2011.

Author contributions: A.L., N.C., N.S., and S.R.L. designed research; A.L., N.C., N.M.L., S.F.B., S.G., H.T., and S.R.L. performed research; A.L., N.C., N.M.L., S.F.B., S.G., H.T., N.S., and S.R.L. analyzed data; A.L. and N.C. wrote the paper.

This work was supported by the Canadian Institutes of Health Research and graduate fellowships to N.L. and S.F.B. from the National Science and Engineering Research Council of Canada.

*A.L. and N.C. contributed equally to this work.

Correspondence should be addressed to Dr. Steven R. Laviolette, Department of Anatomy \& Cell Biology, The Schulich School of Medicine \& Dentistry, University of Western Ontario, London, ON N6A 5C1, Canada. E-mail: Steven.Laviolette@schulich.uwo.ca.

DOI:10.1523/JNEUROSCI.1781-11.2011

Copyright $\odot 2011$ the authors $\quad 0270-6474 / 11 / 3111172-12 \$ 15.00 / 0$ this DAergic VTA $\rightarrow$ BLA projection pathway in terms of opiate reward processing is not known. Unlike the VTA, the BLA itself is not implicated in the primary rewarding effects of opiates as microinfusions of morphine directly into the amygdala fail to produce reinforcing effects (Olmstead and Franklin, 1997). BLA neuronal activity is correlated with the acquisition and recall of opiate-related associative memories (Frenois et al., 2005) and inactivation or lesions of the BLA attenuate cue-induced recall of heroin-seeking behavior (Fuchs and See, 2002), demonstrating a critical role for the BLA during opiate-related learning and memory. In addition to functional connections with the VTA, the BLA sends glutamatergic projections to the NAc, predominantly to the shell (NAshell) subdivision (McDonald, 1991a,b), that modulate NAc neuronal activity (Floresco et al., 2001), modulate the release of DA during emotionally salient events (Stevenson and Gratton, 2003), and facilitate reward-seeking behaviors (Baxter and Murray, 2002; Ambroggi et al., 2008).

Given the role of the BLA in opiate-related memory and its functional connectivity with the mesolimbic system, we hypothesized that DA receptor transmission within the BLA may control the acquisition of opiate-related associative memories by modulating NAc neuronal responses to morphine. Furthermore, given previous evidence demonstrating differential roles for DA transmission during opiate reward processing in the opiate-naive versus opiate-dependent and withdrawn states (Laviolette et al., 2002, 2004), we hypothesized that intra-BLA DA transmission would be critical for opiate reward processing specifically during 
the opiate-dependent and withdrawn state. Surprisingly, we found that DA D1-like and D2-like receptor transmission within the BLA controls the acquisition of opiate reward memory as a direct function of opiate exposure state. Thus, blockade of DA D1 but not D2 transmission blocks opiate reward acquisition in previously opiate-naive animals, whereas this functional arrangement is switched in animals conditioned while opiate-dependent and in withdrawal. Furthermore, behaviorally effective doses of intra-BLA D1 or D2 antagonists blocked neuronal responses to morphine administration specifically within the NAshell striatal subdivision, following the same functional boundary between opiate exposure states. Our results demonstrate a novel switching mechanism between DA D1 versus D2 receptor transmission within the BLA $\rightarrow$ NAshell pathway, controlling opiate reward signaling as a function of opiate exposure state.

\section{Materials and Methods}

Animals and surgical procedures. All experimental procedures were performed in accordance with institutional and governmental regulations for animal care. Male Sprague-Dawley rats (Charles River; 350-400 g at the start of the experiments) were anesthetized with a ketamine ( $80 \mathrm{mg} /$ $\mathrm{ml})$ and xylazine $(6 \mathrm{mg} / \mathrm{ml})$ mixture and placed into a stereotaxic device. For behavioral studies using intracranial microinfusions, stainless steel guide cannulae (22 gauge; Plastics One) were bilaterally implanted into selected brain regions using the following stereotaxic coordinates (in $\mathrm{mm})$ : VTA $\left(10^{\circ}\right.$ angle): from bregma, AP $-5.0, \mathrm{~L} \pm 2.3$; from the dural surface, $\mathrm{V}-8.0$; BLA: from bregma, AP $-3.0, \mathrm{~L} \pm 5.0$; from the dural surface, $\mathrm{V}-8.0$. At the conclusion of the experiments, animals were deeply anesthetized and transcardially perfused with isotonic saline followed by $10 \%$ formalin, and brains were removed and placed in a formalin-sucrose solution before sectioning. Sections were stained with cresyl violet, and VTA or BLA cannulae placements were verified with light microscopy according to the anatomical boundaries defined by Paxinos and Watson (2005). Animals found to have cannulae placements outside of the desired brain regions were excluded from analysis.

Drug treatments. The DA D2 receptor antagonist eticlopride (Sigma), DA D1 receptor antagonist SCH 23390 (Tocris Bioscience), heroin (diacetylmorphine, MacFarlane-Smith), morphine (morphine hydrochloride, MacFarlane Smith), Rp-cAMP (cAMP inhibitor, Biomol), and Sp-cAMP (cAMP activator, Biomol) were dissolved in physiological saline ( $\mathrm{pH}$ adjusted to 7.4). Bilateral BLA or VTA microinfusions ( $0.5 \mu \mathrm{l}$ volume per infusion) were performed over $1 \mathrm{~min}$ via plastic tubing connected to a $1 \mu \mathrm{l}$ Hamilton microsyringe. Injectors were then left in place for an additional $1 \mathrm{~min}$ to ensure adequate diffusion from the injector tip. For intra-VTA morphine experiments, intra-BLA microinfusions of the DA D1 or D2 receptor antagonists were performed immediately before VTA microinfusions of morphine. For cAMP modulation experiments, intra-BLA administrations of Sp-cAMP/Rp-cAMP were coinfused simultaneously with intra-BLA DA receptor drugs. All microinfusions were performed immediately before systemic injections of morphine or saline vehicle, and animals were then placed in the assigned place conditioning environments immediately following systemic injection of morphine or saline; thus, any potential effects of challenge drugs were balanced across both saline and morphine conditioning sessions. For experiments examining the effects of intra-BLA D1 or D2 receptor blockade on morphine reward conditioning, we used a previously established dose of morphine $(5.0 \mathrm{mg} / \mathrm{kg}$, i.p.) that produces a robust conditioned place preference (CPP) for morphine-paired environments (Bishop et al., 2011). Similarly, for experiments examining the effects of intra-BLA D1/D2 blockade on the rewarding effects of intraVTA morphine administration, we used a previously established dose of intra-VTA morphine $(500 \mathrm{ng} / 0.5 \mu \mathrm{l})$ that produces robust CPP (Laviolette et al., 2004; Bishop et al., 2011).

Conditioned place preference procedure. All place conditioning procedures used an unbiased, counterbalanced conditioning protocol as described previously (Laviolette et al., 2002, 2004; Bishop et al., 2011). Briefly, conditioning took place in two environments that differed in color, texture, and smell. One environment was white with a wire mesh floor that was covered with wood chips. The other environment was black with a smooth Plexiglas floor wiped down with a $2 \%$ acetic acid solution before each conditioning session. Drug and saline environmental pairings and treatment order were assigned in a fully counterbalanced manner. As reported previously, animals displayed no baseline preference for either of these environments (Laviolette and van der Kooy, 2003). Furthermore, following place conditioning testing, average times spent in black versus white environments were compared to ensure that no systemic bias existed for either of the two conditioning environments. During conditioning experiments, animals received four morphine-environment and four saline-environment pairings, counterbalanced over $8 \mathrm{~d}$. During CPP testing, animals were placed on a narrow, separate gray zone that separated the two environments, and times spent in each of the two environments were digitally recorded and scored separately for each animal over a 10 min test session.

Induction of opiate dependence and withdrawal. For studies examining behavioral and electrophysiological responses during opiate dependence and withdrawal, animals were trained and/or neurons recorded in a state of heroin dependency and withdrawal as described previously (Laviolette et al., 2002, 2004). Thus, rats received daily $0.5 \mathrm{mg} / \mathrm{kg}$, s.c., injections of heroin commencing $7 \mathrm{~d}$ before the start of conditioning or electrophysiological recording sessions. This rapid protocol for the induction of opiate dependence and withdrawal is advantageous for several reasons. First, as noted above, it produces a state of opiate dependency and withdrawal that is qualitatively and quantitatively similar to that observed after a longer, 3 week morphine-exposure protocol (Laviolette et al., 2002). Second, because animals have chronic, in-dwelling cannulae implantations, a 3 week opiate-exposure protocol would increase the likelihood of developing intracranial infections. Finally, the aversive effects of withdrawal induced by this regimen are qualitatively similar to those observed after a 3 week regimen of morphine administration, which produces aversive motivational effects as well as somatic withdrawal signs (Laviolette et al., 2004). For behavioral studies, rats were conditioned $21 \mathrm{~h}$ after their last heroin injection. During conditioning, this same dose of heroin was administered as a maintenance dose $3.25 \mathrm{~h}$ after the termination of each conditioning session. Over the course of the experiments, animals thus received a total of 15 heroin injections ( 7 before conditioning, 8 during conditioning). For in vivo electrophysiological recording studies, rats experienced the same heroin pretreatment protocol and recording experiments were performed within the same timeframe as the behavioral studies, with neuronal recordings performed in a state of $21 \mathrm{~h}$ of withdrawal from the time of the last heroin injection. For behavioral and electrophysiological studies, yoked controls received saline injections over the same timeframe. For opiate recovery/plasticity experiments, rats received the same $7 \mathrm{~d}$ heroin treatment described above but were then given a $7 \mathrm{~d}$ clearing period during which no heroin was administered. Following this recovery period from opiate exposure, the behavioral experiments were started as described above.

In vivo electrophysiological recordings. Rats were anesthetized with urethane $(1.4-1.5 \mathrm{mg} / \mathrm{kg}$, i.p.) and their femoral vein was cannulated for intravenous administration of pharmacological agents or vehicle. The rats were placed in a stereotaxic frame with body temperature maintained at $37^{\circ} \mathrm{C}$ with a homeothermic blanket. The scalp was retracted and a burr hole was drilled above the NAc and BLA regions. Two glass micropipettes (with an average impedance of 2-8 M $\Omega$ ) filled with $2 \%$ Pontamine Sky Blue solution were lowered into the NAshell [from bregma (in $\mathrm{mm}$ ): $\mathrm{AP}=+1.8 \mathrm{~mm}, \mathrm{ML}= \pm 0.5 \mathrm{~mm}, \mathrm{DV}=-6.5$ to $8 \mathrm{~mm}$ from dura] or the NAcore (from bregma at an $8^{\circ}$ angle: $\mathrm{AP}=+1.8 \mathrm{~mm}, \mathrm{ML}=$ $\pm 2.7 \mathrm{~mm}, \mathrm{DV}=-6.4 \mathrm{~mm}$ ). For intra-BLA microinjections with the D1-like receptor antagonist SCH 23390 or the D2-like receptor antagonist eticlopride, stainless steel guide cannulae of 22 gauge (Plastic One) were implanted into BLA using the same stereotaxic coordinates described above. Extracellular signals were amplified using a MultiClamp 700B amplifier (Molecular Devices) and recorded through a Digidata 1440 A acquisition system (Molecular Devices) using pClamp 10 software. Extracellular recordings were filtered at $1 \mathrm{kHz}$ and sampled at 5 $\mathrm{kHz}$. Spontaneously active NAc neurons in the NAshell and NAcore were simultaneously isolated via separate recording electrodes, and baseline 
activity for both NAcore and NAshell neurons was recorded during the $5 \mathrm{~min}$ period before intra-BLA saline vehicle, SCH 23390 (1.0 g/0.5 1; Tocris Bioscience), or eticlopride ( $1.0 \mathrm{~g} / 0.5 \mathrm{l}$; Sigma) D2 agonist injection (infusion duration $=1 \mathrm{~min}$ ), following which intravenous morphine $(1 \mathrm{mg} / \mathrm{kg})$ or saline was administered. Intra-BLA infusions were performed only when a single NAshell and NAcore neuron was simultaneously isolated for dualchannel recordings. Drug treatments (intraBLA SCH 23390 or eticlopride) and morphine were performed only once per rat; thus, only two neurons were recorded per rat for experimental consistency. The response patterns of isolated NAshell or NAcore neurons to morphine administration were determined by comparing the neuronal frequency rates between the $5 \mathrm{~min}$ prerecording versus postrecording epochs. Initial pilot studies examining the effects of intravenous morphine administration on spontaneous NAc neuronal activity patterns revealed that doses higher than $1 \mathrm{mg} /$ $\mathrm{kg}$, i.v., resulted in a lethal interaction with the urethane anesthesia. Hence, for all subsequent recording experiments, we used a dose of $1 \mathrm{mg} / \mathrm{kg}$, i.v., morphine. For histological analysis of extracellular neuronal recording sites, recording electrode positions were marked with an iontophoretic deposit of Pontamine Sky Blue dye $(-20$ $\mu \mathrm{A}$; with continuous current for 10-15 min) and perfused transcardially with isotonic saline followed by $10 \%$ formalin. Brains were removed and stored in a $25 \%$ sucrose-formalin solution before sectioning $(40-\mu \mathrm{m}-$ thick sections) on a freezing cryotome. Following this, sections were stained with cresyl violet and injection and/or neuronal recording sites were confirmed with light microscopy.

Statistical analysis. All data were analyzed with one-, two-, or threeway ANOVAs or Student's $t$ tests where appropriate. Post hoc analyses were performed with Bonferonni-Dunn's tests or Tukey's tests where appropriate.

\section{Results}

Effects of intra-BLA DA receptor blockade on morphine reward encoding in the previously opiate-naive state

To examine how blockade of intra-BLA D1 or D2 receptors may influence the acquisition of opiate reward CPP, we performed intra-BLA bilateral microinfusions of a DA D1 (SCH 23390, $0.001-1.0 \mu \mathrm{g} / 0.5 \mu \mathrm{l}$ ) or D2 receptor antagonist (eticlopride, $0.01-1.0 \mu \mathrm{g} / 0.5 \mu \mathrm{l}$ ) in previously opiate-naive rats, using a previously established rewarding dose of systemic morphine (5.0 $\mathrm{mg} / \mathrm{kg}$, i.p.; Bishop et al., 2011). Postexperimental histological analyses revealed bilateral cannulae placements within the BLA as defined by Paxinos and Watson (2005). In Figure $1 A$, a representative microphotograph shows a typical injector tip placement in the BLA. We present an illustrative schematic (Fig. $1 B, C$ ) showing typical bilateral microinfusion sites within the BLA from four representative experimental groups. Rats found to have cannulae placements outside the anatomical boundaries of the BLA were excluded from behavioral analysis.

Examining the effects of DA D1 versus D2 receptor blockade within the BLA on the acquisition of morphine $(5 \mathrm{mg} / \mathrm{kg}$, i.p.) CPP revealed dissociable effects of intra-BLA D1 versus D2 receptor blockade. In Figure $2 A$, results of morphine CPP testing demonstrated that intra-BLA microinfusions of the D1 antagonist SCH 23390 dose-dependently $(0.01,0.1$, and $1.0 \mu \mathrm{g} / 0.5 \mu \mathrm{l})$ blocked morphine CPP in opiate-naive animals. Two-way ANOVA revealed a significant main effect of treatment (systemic morphine vs saline) on times spent in saline- versus morphine- paired environments $\left(F_{(1,71)}=6.72, p<0.05\right)$ (Fig. $\left.2 A\right)$. Post hoc comparisons revealed that saline control rats $(n=7, p<0.01)$ and the group receiving the lowest dose $(0.001 \mu \mathrm{g} / 0.5 \mu \mathrm{l})$ of intra-BLA SCH23390 $(n=9, p<0.05)$ before systemic morphine $(5 \mathrm{mg} / \mathrm{kg})$ showed significant morphine CPP. However, in groups receiving the three higher doses of SCH 23390 [0.01 $(n=$ $7), 0.1(n=8), 1.0(n=8) \mu \mathrm{g} / 0.5 \mu \mathrm{l})$, morphine CPP was absent ( $p$ values $>0.05$ ) (Fig. $2 A$ ). Also, time spent in morphine-paired environments in animals receiving the two highest doses of intraBLA SCH $23390(0.1-1.0 \mu \mathrm{g} / 0.5 \mu \mathrm{l})$ was significantly decreased relative to times spent in morphine environments in saline control animals ( $p$ values $<0.05$ ). We next performed intra-BLA bilateral microinfusions of the DA D2 receptor antagonist (eticlopride, $0.01-1.0 \mu \mathrm{g} / 0.5 \mu \mathrm{l}$ ) in previously opiate-naive animals, challenging the same morphine dose $(5.0 \mathrm{mg} / \mathrm{kg}$, i.p.). As shown in Figure 2 $B$, CPP test results revealed that intra-BLA eticlopride administration failed to disrupt morphine reward in the opiatenaive state. Two-way ANOVA showed a significant main effect of treatment (systemic morphine vs saline) on times spent in salineversus morphine-paired environments $\left(F_{(1,55)}=58.42, p<\right.$ 0.001). Post hoc comparisons showed that no dose of intra-BLA eticlopride (0.01, 0.1, and $1.0 \mu \mathrm{g} / 0.5 \mu \mathrm{l}$ ) (Fig. $2 B$ ) influenced morphine reward as all groups demonstrated a strong morphine $\mathrm{CPP}(n=7, p<0.01 ; n=6, p<0.05 ; n=7, p<0.01)$. Thus, intra-BLA D2 receptor blockade failed to block morphine reward learning in the opiate-naive state.

\section{Effects of intra-BLA DA receptor blockade on morphine reward in the opiate-dependent/withdrawn state}

We next examined the effects of intra-BLA D1 or D2 receptor blockade in rats conditioned in the opiate-dependent/withdrawn state (see Materials and Methods). For groups receiving intraBLA microinfusions of the D1 antagonist (SCH 23390) using our previously established (Fig. 2) behaviorally effective dose range $(0.1-1.0 \mu \mathrm{g} / 0.5 \mu \mathrm{l})$ before receiving morphine $(5 \mathrm{mg} / \mathrm{kg}$, i.p.), two-way ANOVA revealed a significant main effect of treatment (saline vs morphine) on times spent in saline- versus morphinepaired environments $\left(F_{(1,43)}=182.19, p<0.001\right)$ (Fig. 3A). Post hoc comparisons showed that, similar to saline controls $(n=7$, $p<0.01)$, rats receiving the effective doses $(0.1-1.0 \mu \mathrm{g} / 0.5 \mu \mathrm{l})$ of intra-BLA SCH 23390 displayed robust morphine CPP $(0.1 \mu \mathrm{g} /$ $0.5 \mu \mathrm{l}, n=8 ; 1.0 \mu \mathrm{g} / 0.5 \mu \mathrm{l}, n=7$; $p$ values $<0.01)$. However, in 


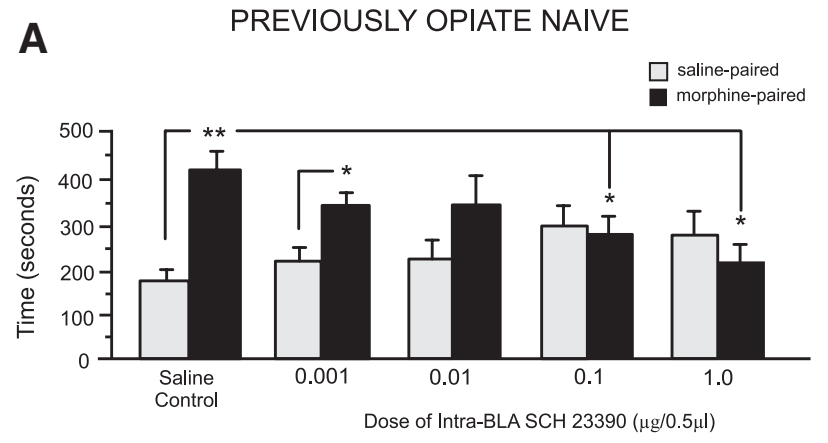

B PREVIOUSLY OPIATE NAIVE

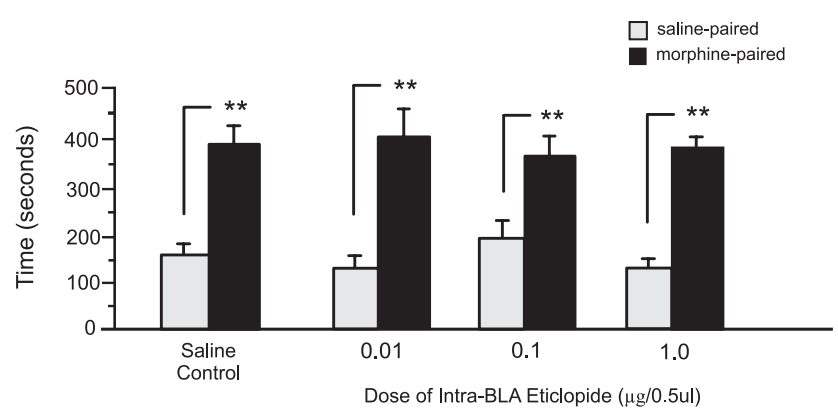

Figure 2. Effects of intra-BLA DA D1-like or D2-like receptor blockade on opiate reward conditioning in the previously opiate-naive state. $A$, Relative to intra-BLA saline controls, rats receiving bilateral intra-BLA microinfusions of the D1-like receptor antagonist SCH 23390 $(0.001-1.0 \mu \mathrm{g} / 0.5 \mu \mathrm{l})$ demonstrated a dose-dependent block of morphine-related CPP when tested postconditioning. $\boldsymbol{B}$, In contrast, relative to intra-BLA saline controls, rats receiving bilateral intra-BLA microinfusions of the D2-like receptor antagonist eticlopride $(0.01-1.0 \mu \mathrm{g} /$ $0.5 \mu \mathrm{l})$ demonstrated robust (PP for morphine-paired environments at testing. For this and all subsequent figures: ${ }^{*} p<0.05,{ }^{* *} p<0.01$; and error bars represent the SEM.

contrast to what we observed in opiate-naive rats (Fig. $2 \mathrm{~A}$ ), intraBLA SCH 23390 failed to block morphine CPP in rats conditioned in the opiate-dependent/withdrawn state. Next, opiate-dependent/ withdrawn rats received bilateral intra-BLA microinfusion of eticlopride, using the previously established behaviorally effective dose range $(0.1-1.0 \mu \mathrm{g} / 0.5 \mu \mathrm{l}$ ) (Fig. $2 B$ ), before receiving morphine (5 $\mathrm{mg} / \mathrm{kg}$, i.p.) (Fig. $3 B$ ). Two-way ANOVA revealed a significant group (intra-BLA saline vs eticlopride) by treatment (systemic saline vs morphine) interaction on times spent in saline- versus morphinepaired environments $\left(F_{(2,41)}=6.14, p<0.01\right)$. Post hoc tests revealed that animals receiving the lower dose $(0.1 \mu \mathrm{g} / 0.5 \mu \mathrm{l}, n=$ $6, p<0.01)$ of intra-BLA eticlopride or saline $(n=7, p<0.05)$ showed significant morphine CPP. However, rats receiving the higher dose of eticlopride $(1.0 \mu \mathrm{g} / 0.5 \mu \mathrm{l})$ demonstrated no morphine CPP $(n=7, p>0.05)$. Furthermore, times spent in morphine-paired environments in animals receiving the highest dose of intra-BLA eticlopride $(1.0 \mu \mathrm{g} / 0.5 \mu \mathrm{l})$ were significantly decreased relative to times spent in morphine environments in saline control animals $(n=7, p<0.05)$ (Fig. $3 B)$. Thus, during the opiate-dependent/withdrawn state, the acquisition of morphine CPP requires intra-BLA D2-like but not D1-like receptor transmission, a functional reversal of the effects observed in the opiate-naive state.

Effects of BLA DA receptor blockade on intra-VTA morphine reward encoding

We next examined how manipulation of intra-BLA DA D1 or D2 receptor transmission might modulate opiate reward signals originating directly from the VTA, using intra-VTA morphine
A

OPIATE DEPENDENT/WITHDRAWN

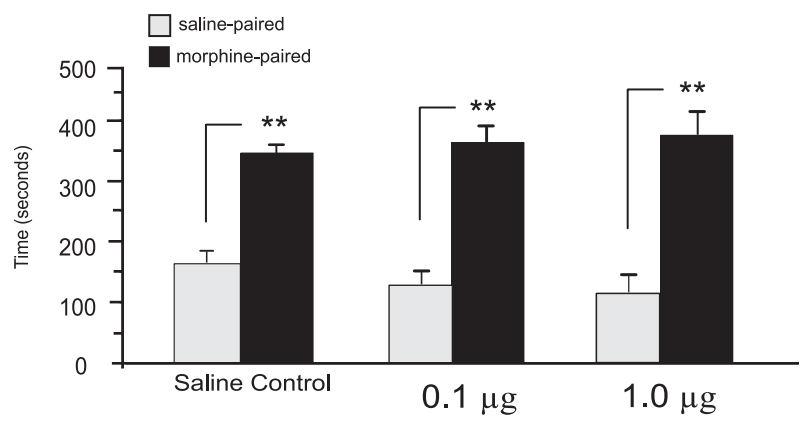

Dose of intra-BLA SCH23390 $(\mu \mathrm{g} / 0.5 \mu \mathrm{l})$

B

\section{OPIATE DEPENDENT/WITHDRAWN}
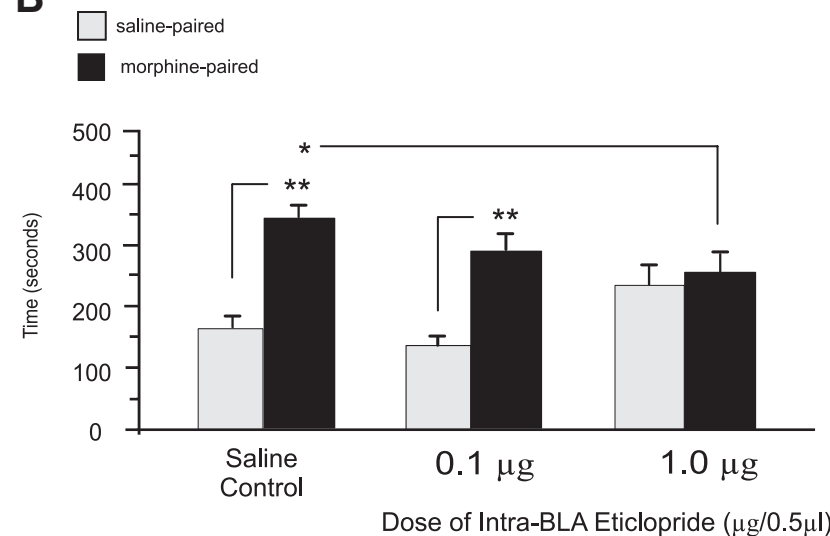

Figure 3. Effects of intra-BLA DA D1-like or D2-like receptor blockade on opiate reward conditioning in opiate-dependent and withdrawn rats. A, Relative to intra-BLA saline controls, opiate-dependent and withdrawn rats receiving bilateral intra-BLA microinfusions of the D1like receptor antagonist SCH $23390(0.1-1.0 \mu \mathrm{g} / 0.5 \mu \mathrm{l})$ demonstrated robust (PP for morphine-paired environments at testing. $\boldsymbol{B}$, In contrast, relative to intra-BLA saline controls, opiate-dependent and withdrawn rats receiving bilateral intra-BLA microinfusions of the D2like receptor antagonist eticlopride $(0.1-1.0 \mu \mathrm{g} / 0.5 \mu \mathrm{l})$ demonstrated a dose-dependent blockade of morphine CPP when tested postconditioning.

(500 ng/0.5 $\mu \mathrm{l}$ ) administration (see Materials and Methods). This dose of intra-VTA morphine produces robust CPP for morphine-paired environments (Nader and van der Kooy, 1997; Laviolette et al., 2004). Figure $4 A$ shows a microphotograph demonstrating representative bilateral intra-VTA microinfusion sites, and an illustrative schematic in Figure $4 B$ shows intra-VTA microinjector tip locations from two representative experimental groups. Blockade of intra-BLA D1 receptor transmission produced the same double dissociation for the encoding of intraVTA morphine reward signaling as that observed in our systemic morphine experiments (Fig. 4C). Comparing intra-VTA morphine CPP test results, two-way ANOVA revealed an interaction between group (saline control vs drug treatment groups) and treatment (systemic saline vs morphine) on times spent in salineversus morphine-paired environments $\left(F_{(1,40)}=9.32, p<0.01\right)$ (Fig. 4C). Post hoc tests revealed that while opiate-naive animals receiving intra-BLA saline $(n=8, p<0.05)$ and opiatedependent animals receiving intra-BLA D1 antagonist (SCH 23390, $1.0 \mu \mathrm{g} / 0.5 \mu \mathrm{l})$ before intra-VTA morphine $(0.5 \mu \mathrm{g} / 0.5 \mu \mathrm{l})$ demonstrated significant CPP for the intra-VTA morphinepaired environments $(n=7, p<0.01)$, previously opiate-naive rats that received intra-BLA SCH 23390 at the same dose $(1.0$ $\mu \mathrm{g} / 0.5 \mu \mathrm{l})$ demonstrated no morphine CPP $(n=8, p>0.05)$. 

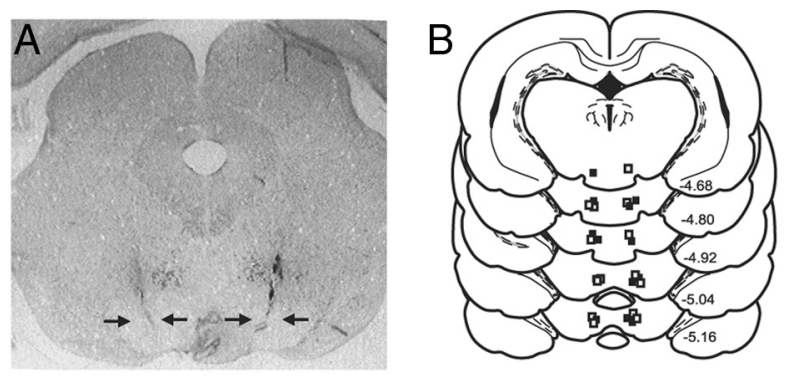
C INTRA-BLAD1 RECEPTOR BLOCKADE
VS. INTRA-VTA MORPHINE
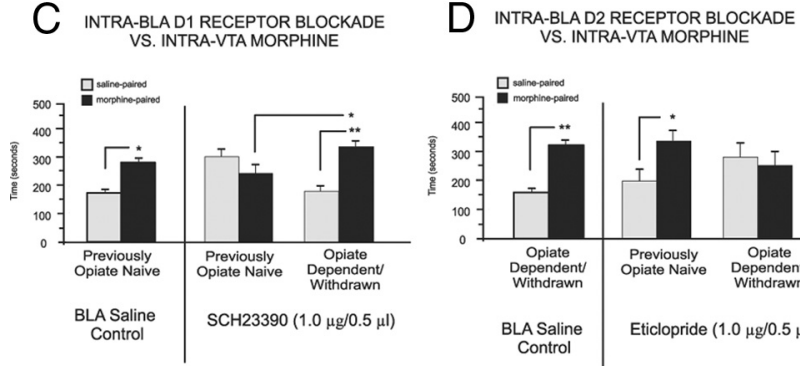
VS. INTRA-VTA MORPHINE

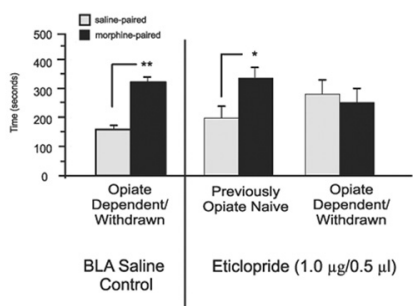

Figure 4. Intra-VTA microinfusion placements and effects of intra-BLA D1-like or D2-like receptor blockade on intra-VTA morphine reward processing. $A$, Microphotograph showing representative bilateral intra-VTA injector tip locations. $\boldsymbol{B}$, Schematic representation of representative intra-VTA bilateral injector locations. $\mathbf{\square}=$ Previously opiate-naive rats receiving intra-BLA SCH 23390 (1.0 $\mu \mathrm{g} / 0.5 \mu \mathrm{l}) ; \square=$ opiate-dependent/withdrawn rats receiving intra-BLA eticlopride $(1 \mu \mathrm{g} / 0.5 \mu \mathrm{l})$. C, Intra-VTA morphine produces robust CPP for intra-VTA morphine environments $(500 \mathrm{ng} / 0.5 \mu \mathrm{l})$ in previously opiate-naive control rats receiving intraBLA saline. However, intra-BLA SCH $23390(1.0 \mu \mathrm{g} / 0.5 \mu \mathrm{l})$ blocks the acquisition of CPP to environments paired with intra-VTA morphine $(500 \mathrm{ng} / 0.5 \mu \mathrm{l})$ only in previously opiate-naive rats. $\boldsymbol{D}$, Intra-VTA morphine produces robust CPP for intra-VTA morphine ( $500 \mathrm{ng} / 0.5 \mu \mathrm{l})$ environments in opiate-dependent/withdrawn control rats receiving intra-BLA saline. However, intra-BLA eticlopride $(1.0 \mu \mathrm{g} / 0.5 \mu \mathrm{l})$ blocks the acquisition of CPP to environments paired with intra-VTA morphine $(500 \mathrm{ng} / 0.5 \mu \mathrm{l})$ only in opiate-dependent/withdrawn rats but not in previously opiate-naive rats.

Furthermore, morphine CPP in previously opiate-naive rats treated with intra-BLA SCH23390 was significantly depressed relative to that in opiate-dependent/withdrawn rats $(p<0.01)$. Thus, intra-BLA D1-like receptor blockade blocks the encoding of morphine reward signaling from the VTA in the opiate-naive but not opiate-dependent/withdrawn state, consistent with the effects observed with systemic morphine. Blockade of intra-BLA D2 receptor transmission produced the same double dissociation for the encoding of intra-VTA morphine reward signaling as that observed for systemic morphine. Two-way ANOVA revealed a significant interaction between group (saline control vs drug treatment groups) and treatment (systemic saline vs morphine) on times spent in saline- versus morphine-paired environments $\left(F_{(2,45)}=4.24, p<0.05\right)$. Post hoc analyses revealed that opiatenaive rats receiving intra-BLA saline showed a robust CPP for intra-VTA morphine-paired environments $(n=7, p<0.01)$. However, in groups receiving intra-BLA eticlopride $(1.0 \mu \mathrm{g} / 0.5$ $\mu \mathrm{l})$, D2 receptor blockade failed to prevent the encoding of intraVTA morphine CPP in opiate-naive rats $(n=8, p<0.05)$ but blocked intra-VTA morphine CPP when conditioned in the opiate-dependent/withdrawn state $(n=8, p>0.05)$ (Fig. $4 D)$.

\section{Plasticity of the intra-BLA DA D1/D2 switch after recovery from opiate exposure}

To determine whether chronic opiate exposure induced a permanent switch in the functional roles of intra-BLA D1 or D2 receptor transmission during opiate reward encoding, separate experimental groups received the same chronic opiate pretreat-
A

INTRA-BLA D1 RECEPTOR BLOCKADE $\mathrm{SCH} 23390(1.0 \mu \mathrm{g} / 0.5 \mu \mathrm{l})$

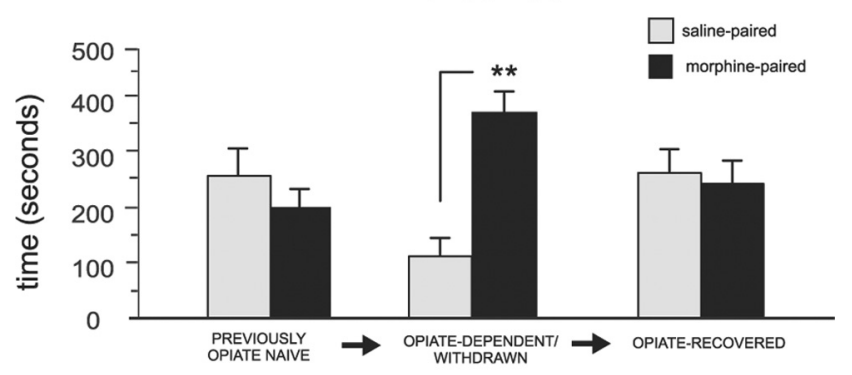

B

INTRA-BLA D2 RECEPTOR BLOCKADE eticlopride $(1.0 \mu \mathrm{g} / 0.5 \mu \mathrm{l})$

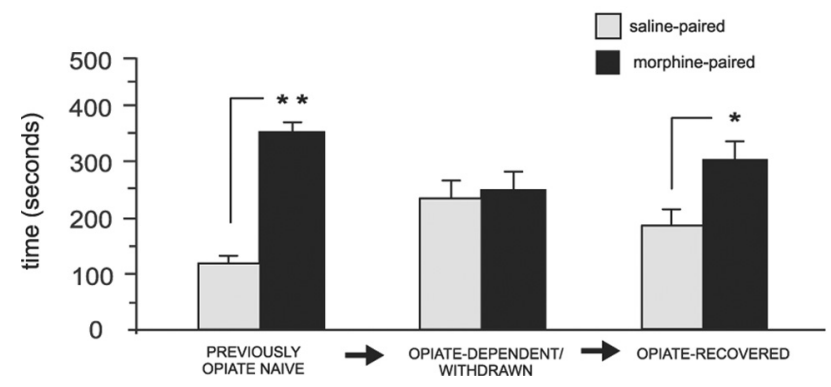

Figure 5. Reversal of intra-BLA DA D1-like and D2-like receptor functional switching follows opiate exposure recovery. $A$, Intra-BLA DA D1-like receptor blockade (SCH 23390, $1 \mu \mathrm{g} / 0.5 \mu \mathrm{l})$ blocks morphine CPP in previously opiate-naive and in opiate-recovered rats, but not in rats trained in the opiate-dependent and withdrawn state (see Materials and Methods). $\boldsymbol{B}$, Intra-BLA DA D2-like receptor blockade (eticlopride $1 \mu \mathrm{g} / 0.5 \mu \mathrm{ll}$ ) does not block morphine CPP in previously opiate-naive rats, but blocks opiate reward CPP in rats trained in the opiate-dependent and withdrawn state but not in rats chronically exposed to opiates and allowed to recover.

ment described previously, but they were then allowed to recover from opiate exposure before the beginning of morphine conditioning with intra-BLA D1/D2 receptor blockade or saline (see Materials and Methods). Analysis of CPP behavioral results revealed that in rats exposed to opiates then allowed to recover, intra-BLA D1 receptor blockade produced the same effects as those observed in the opiate-naive state (Fig. 5A). Two-way ANOVA revealed a significant interaction between groups ( 3 states of opiate exposure: previously opiate-naive, $n=8$; opiatedependent/withdrawn, $n=7$; or opiate-recovered, $n=7$ ) and treatment (systemic saline vs morphine) on times spent in saline versus morphine $\left(5 \mathrm{mg} / \mathrm{kg}\right.$, i.p.) environments $\left(F_{(2,41)}=7.24\right.$, $p<0.01)$. Post hoc analyses showed that opiate-dependent animals receiving intra-BLA microinfusion of SCH $23390(1.0 \mu \mathrm{g} /$ $0.5 \mu \mathrm{l}$, previously established dose) showed robust morphine CPP $(p<0.01)$. However, with the same drug treatment (SCH $23390,1.0 \mu \mathrm{g} / 0.5 \mu \mathrm{l}$ ), neither opiate-naive nor opiate-recovered rats displayed morphine CPP ( $p$ values $>0.05$ ), demonstrating that chronic opiate exposure induces a transient switch in the functional effects of intra-BLA D1 receptor blockade, which reverts to the functionally opiate-naive state once opiate exposure recovery has occurred. Examining the effects of intra-BLA D2 receptor blockade in rats chronically exposed to opiates then allowed to recover, intra-BLA D2 receptor blockade produced the same effects as those observed in the opiate-naive state and failed to block morphine CPP (Fig. 5B). ANOVA showed a significant interaction between groups ( 3 states of opiate exposure: previously opiate-naive, $n=7$; opiate-dependent/withdrawn, $n=7$; opiate-recovered, $n=7$ ) and treatment (systemic saline vs morphine) on times spent in saline- versus morphine-paired envi- 
ronments $\left(F_{(2,41)}=6.51, p<0.01\right)$. Post hoc comparisons showed that when microinfusions of the intra-BLA D2 antagonist (eticlopride, $1.0 \mu \mathrm{g} / 0.5 \mu \mathrm{l}$ ) before systemic morphine $(5 \mathrm{mg} / \mathrm{kg}$, i.p.) was performed across groups (Fig. $5 B$ ), opiate-dependent rats showed no morphine CPP ( $p>0.05)$, whereas opiate-naive and opiate-recovered rats displayed robust morphine CPP ( $p$ values $<0.01$ and 0.05 , respectively). Thus, similar to the effects of intraBLA SCH 23390 (Fig. 5A), once recovery from chronic opiate exposure had occurred, the functional effects of D2 receptor transmission within the BLA reverted to the opiate-naive state.

\section{Pharmacological modulation of intra-BLA cAMP levels reverses the behavioral effects of D1 or D2 receptor blockade on opiate reward encoding}

We next examined the effects of protein kinase A (PKA) and cAMP modulation on intra-BLA DA receptor transmission during opiate reward conditioning. Because activation of D1 receptors is well established to increase downstream cAMP levels (Senogles et al., 1988), we hypothesized that intra-BLA administration of D1 antagonists would cause a reduction of downstream PKA/cAMP signaling. Accordingly, we coadministered the PKA/ cAMP activator Sp-cAMP (see Materials and Methods) to determine whether counteracting the effects of intra-BLA D1 blockade (PKA/cAMP inhibition) would rescue the observed blockade of morphine CPP, previously observed in opiate-naive rats (Fig. 2). Behavioral analysis revealed that intra-BLA coadministration of Sp-cAMP with the behaviorally effective dose of SCH 23390 (1.0 $\mu \mathrm{g} / 0.5 \mu \mathrm{l}$ ) completely reversed the effects of intra-BLA D1 receptor blockade on opiate reward encoding, with rats now showing significant morphine CPP (Fig. 6A). Two-way ANOVA showed a significant interaction between groups (intra-BLA SCH23390 alone or Sp-cAMP coadministration) and treatment (saline vs morphine) on times spent in saline versus morphine environments $\left(F_{(1,29)}=14.69, p<0.01\right)$ (Fig. $\left.6 A\right)$. Post hoc comparisons revealed that intra-BLA D1 SCH23390 blocked morphine CPP $(n=7, p>0.05)$. In contrast, intra-BLA coadministration of the PKA/cAMP activator (Sp-cAMP, $0.5 \mu \mathrm{g} / 0.5 \mu \mathrm{l}$ ) with SCH 23390 $(1.0 \mu \mathrm{g} / 0.5 \mu \mathrm{l})$ rescued morphine-induced $\mathrm{CPP}$, with rats now displaying a strong morphine $\mathrm{CPP}(n=8, p<0.01)$ (Fig. $6 A)$. Also, relative to animals receiving intra-BLA SCH 23390 alone, animals that received coadministration of SCH 23390 with SpcAMP spent significantly more time in morphine-paired environments $(n=8, p<0.05)$. We next ran a separate experimental group to determine whether intra-BLA cAMP/PKA inhibition in and of itself would mimic the functional effects of intra-BLA D1 receptor blockade (inhibition of $\mathrm{PKA} / \mathrm{cAMP}$ activity) on morphine CPP by administering a PKA/cAMP inhibitor (Rp-cAMP, $500 \mathrm{ng} / 0.5 \mu \mathrm{l}$ ) alone versus morphine $(5 \mathrm{mg} / \mathrm{kg}$, i.p.) in previously opiate-naive rats $(n=8)$. Similar to results observed with intra-BLA SCH 23390, pharmacological inhibition of PKA/ cAMP blocked morphine CPP in previously opiate-naive rats $\left(t_{(7)}=0.42, p>0.05\right)$ (Fig. $6 A$ ). Thus, the functional effects of intra-BLA D1 receptor blockade depend on inhibition of PKA/ cAMP activity and can be reproduced and/or reversed by concomitant inhibition or activation of cAMP/PKA signaling directly within the BLA.

In contrast to the effects of D1 receptor activation, D2 receptor activation is known to inhibit PKA/cAMP signaling (Senogles et al., 1988), whereas D2 antagonist administration has been shown to produce the opposite functional effect (increased PKA/ cAMP activity; e.g., Dwivedi et al., 2002). Thus, we tested whether concomitant inhibition PKA/cAMP signaling may reverse the functional effects of intra-BLA D2 receptor blockade on mor-
A

Intra-BLA D1 Receptor Blockade PREVIOUSLY OPIATE NAIVE
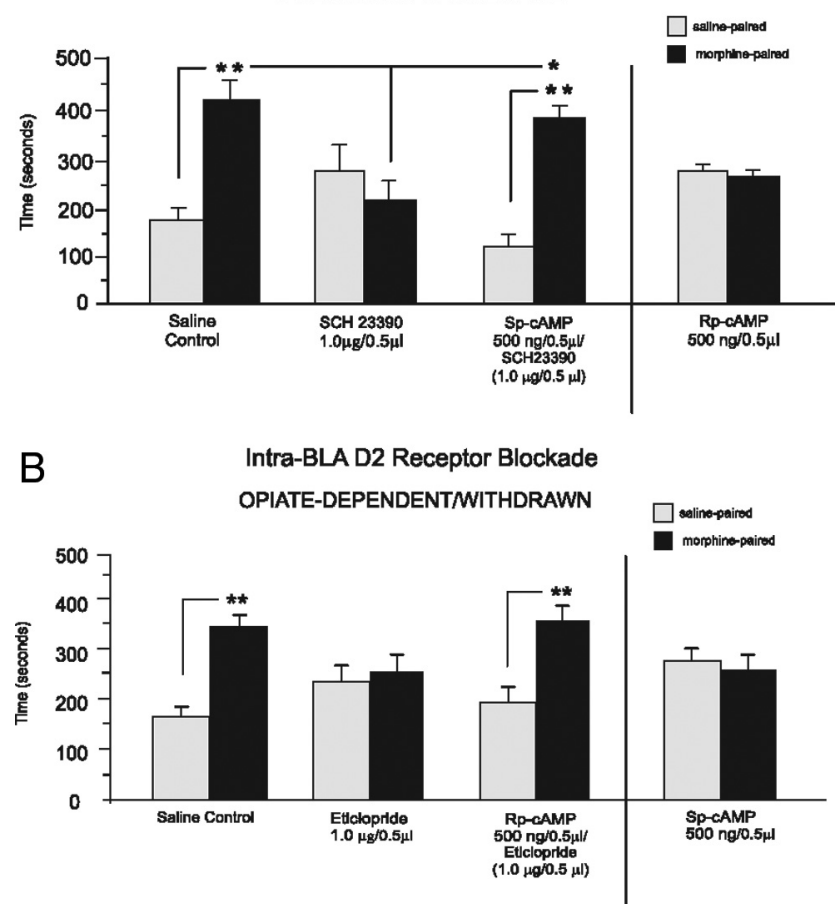

Figure 6. Intra-BLA comodulation of PKA/CAMP signaling modulates the functional effects of intra-BLA D1-like and D2-like receptor blockade during opiate reward CPP conditioning. $A$, In rats trained in the opiate-naive state, intra-BLA coadministration of the D1 antagonist SCH23390 $(1.0 \mu \mathrm{g} / 0.5 \mu \mathrm{l})$ with the PKA/CAMP inhibitor Rp-CAMP $(500 \mathrm{ng} / 0.5 \mu \mathrm{l})$ reverses the behavioral effects of $D 1$ receptor blockade on morphine $C P P$, relative to rats receiving intra-BLA SCH23390 alone. Furthermore, intra-BLA administration of Rp-CAMP alone replicates the behavioral effects of intra-BLA D1 receptor blockade and blocks morphine CPP in rats trained in the opiate-naive state. $\boldsymbol{B}$, In rats trained in the opiate-dependent/withdrawn state, intra-BLA coadministration of the D2 antagonist eticlopride $(1.0 \mu \mathrm{g} / 0.5 \mu \mathrm{l})$ with the PKA/CAMP activator Sp-cAMP $(500 \mathrm{ng} / 0.5 \mu \mathrm{l})$ reverses the behavioral effects of D2 receptor blockade on morphine $(5 \mathrm{mg} / \mathrm{kg}$, i.p) CPP, relative to rats receiving intra-BLA eticlopride alone. Furthermore, intra-BLA administration of Sp-cAMP alone, replicates the behavioral effects of intra-BLA D2 receptor blockade and completely blocks morphine CPP.

phine reward. Using our previously effective dose of eticlopride $(1.0 \mu \mathrm{g} / 0.5 \mu \mathrm{l})$, we coadministered the cAMP inhibitor (RpcAMP, $500 \mathrm{ng} / 0.5 \mu \mathrm{l}$ ) with eticlopride to determine whether counteracting the effects of intra-BLA D2 blockade (PKA/cAMP activation) would reverse our previously observed D2-receptormediated block of morphine CPP in opiate-dependent/withdrawn rats (Fig. $3 B$ ). Behavioral analysis revealed that intra-BLA inhibition of PKA/cAMP reversed the effects of intra-BLA eticlopride on opiate reward encoding (Fig. 6B). Two-way ANOVA revealed a significant main effect of treatment (saline vs morphine) on times spent in saline- versus morphine-paired environments $\left(F_{(1,29)}=4.67, p<0.05\right)$. Post hoc comparisons revealed that opiate-dependent rats treated with intra-BLA eticlopride $(1.0 \mu \mathrm{g} / 0.5 \mu \mathrm{l})$ did not show morphine CPP $(5 \mathrm{mg} / \mathrm{kg}$, i.p., $n=7, p>0.05)$. However, rats treated with coadministration of the intra-BLA PKA/cAMP inhibitor (Rp-cAMP, $500 \mathrm{ng} /$ $0.5 \mu \mathrm{l})$ and eticlopride $(1.0 \mu \mathrm{g} / 0.5 \mu \mathrm{l})$ demonstrated robust morphine CPP $(n=8, p<0.05)$. Thus, similar to the effects reported with intra-BLA D1 receptor blockade, inhibition of intra-BLA PKA/cAMP levels was able to reverse the effects of intra-BLA D2 receptor blockade on opiate reward encoding in the opiate-dependent and withdrawn state. Again, we ran a separate experimental group to determine whether intra-BLA PKA/ 
cAMP activation in and of itself would mimic the functional effects of intra-BLA D2 receptor blockade (inhibition of PKA/ cAMP activity) on opiate reward CPP in the opiate-dependent/ withdrawn state by administering the PKA/cAMP activator (SpcAMP, $500 \mathrm{ng} / 0.5 \mu \mathrm{l}$ ) alone versus morphine $(5 \mathrm{mg} / \mathrm{kg}$, i.p.) in opiate-dependent/withdrawn rats $(n=8)$. Similar to the results observed with intra-BLA eticlopride, activation of PKA/cAMP blocked morphine CPP in opiate-dependent/withdrawn rats $\left(t_{(7)}=0.81, p>0.05\right)$ (Fig. $\left.6 B\right)$.

\section{Effects of intra-BLA DA D1 or D2 receptor blockade on nucleus accumbens neuronal responses to morphine in the opiate-naive state}

The above described behavioral studies (Figs. 2, 3) used a conditioning dose of $5 \mathrm{mg} / \mathrm{kg}$, i.p., morphine, as noted in the Materials and Methods section, but due to interactions with the urethane anesthesia, the highest dose of intravenous morphine that could be used for electrophysiological recordings of NAc neurons was 1 $\mathrm{mg} / \mathrm{kg}$. To ensure that our previously established effective doses of intra-BLA SCH 23390 or eticlopride would produce similar dissociable effects on morphine reward encoding for this lower dose of morphine ( $1 \mathrm{mg} / \mathrm{kg}$, i.v.), we ran separate control experiments challenging the behavioral effects of this lower dose of morphine ( $1 \mathrm{mg} / \mathrm{kg}$, i.p.) with our previously described doses of intra-BLA SCH $23390(1.0 \mu \mathrm{g} / 0.5 \mu \mathrm{l})$ or eticlopride $(1.0 \mu \mathrm{g} / 0.5$ $\mu \mathrm{l})$. For control rats conditioned in the opiate-naive state, twoway ANOVA revealed a significant main effect of group (intraBLA saline, $n=6$; intra-BLA SCH 23390, $n=7$; or intra-BLA eticlopride, $n=6)$ on times spent in morphine versus saline environments $\left(F_{(2,37)}=3.53, p<0.05\right)$. Post hoc analyses revealed that whereas rats receiving intra-BLA saline or intra-BLA eticlopride $(1.0 \mu \mathrm{g} / 0.5 \mu \mathrm{l})$ spent significantly greater time in morphine relative to saline environments ( $p$ values $<0.05)$, rats receiving intra-BLA SCH23390 $(1.0 \mu \mathrm{g} / 0.5 \mu \mathrm{l})$ did not show any morphine environment preference relative to saline environments $(p>0.05)$. For control rats conditioned in the opiatedependent/withdrawn state, two-way ANOVA revealed a significant main effect of group (intra-BLA saline, $n=6$; intraBLA SCH 23390, $n=6$; or intra-BLA eticlopride, $n=6$ ) on times spent in morphine versus saline environments $\left(F_{(2,37)}=15.8, p<\right.$ 0.001). Post hoc analyses revealed that whereas rats receiving intra-BLA saline or intra-BLA SCH $23390(1.0 \mu \mathrm{g} / 0.5 \mu \mathrm{l})$ spent significantly greater time in morphine $(1 \mathrm{mg} / \mathrm{kg}$, i.p.) relative to saline environments ( $p$ values $<0.05$ ), rats receiving intra-BLA eticlopride $(1.0 \mu \mathrm{g} / 0.5 \mu \mathrm{l})$ did not show any morphine environment preference relative to saline environments $(p>0.05)$. Thus, consistent with our previous results using a higher conditioning dose of morphine (5 mg/kg, i.p.) (Figs. 2, 3), these same doses of intra-BLA SCH23390 or eticlopride effectively blocked morphine reward encoding for a lower dose of systemic morphine (1 mg/kg, i.p.) (Table 1$)$.

We next performed single-unit extracellular in vivo neuronal recordings simultaneously within the NAshell and NAcore divisions of the NAc to examine whether intra-BLA D1 or D2 receptor blockade would modulate neuronal responses to morphine administration (see Materials and Methods) using our previously established behaviorally effective doses of either SCH $23390(1.0 \mu \mathrm{g} / 0.5 \mu \mathrm{l})$ or eticlopride $(1.0 \mu \mathrm{g} / 0.5 \mu \mathrm{l})$. We sampled a total of 144 neurons ( $n=72$ rats) within the nucleus accumbens, including 72 neurons that were isolated within the NAshell division and 72 neurons that were isolated within the NAcore. In Figure 7, histological analyses of representative NAshell and NAcore recording sites and intra-BLA
Table 1. Summary of behavioral CPP conditioning effects following intra-BLA saline, eticlopride $(1.0 \mu \mathrm{g} / 0.5 \mu \mathrm{l})$, or SCH $23390(1.0 \mu \mathrm{g} / 0.5 \mu \mathrm{l})$ versus a dose of 1 $\mathrm{mg} / \mathrm{kg}$, i.p., morphine

\begin{tabular}{lll}
\hline & \multicolumn{1}{l}{ Time $(\mathrm{s})$} & \\
\cline { 2 - 3 } Group & Saline environment & $\begin{array}{l}\text { Morphine environment } \\
(1 \mathrm{mg} / \mathrm{kg})\end{array}$ \\
\hline Opiate naive & \\
$\quad$ Intra-BLA saline & $178 \pm 22$ & $347 \pm 33$ \\
$\quad$ Intra-BLA eticlopride & $211 \pm 45$ & $362 \pm 24$ \\
$\quad$ Intra-BLA SCH 23390 & $246 \pm 51$ & $238 \pm 47$ \\
Opiate dependent/withdrawn & & \\
$\quad$ Intra-BLA saline & $169 \pm 31$ & $316 \pm 27$ \\
Intra-BLA eticlopride & $237 \pm 48$ & $246 \pm 51$ \\
Intra-BLA SCH 23390 & $148 \pm 22$ & $326 \pm 34$ \\
\hline
\end{tabular}

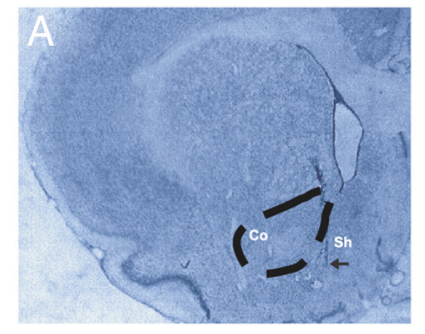

B
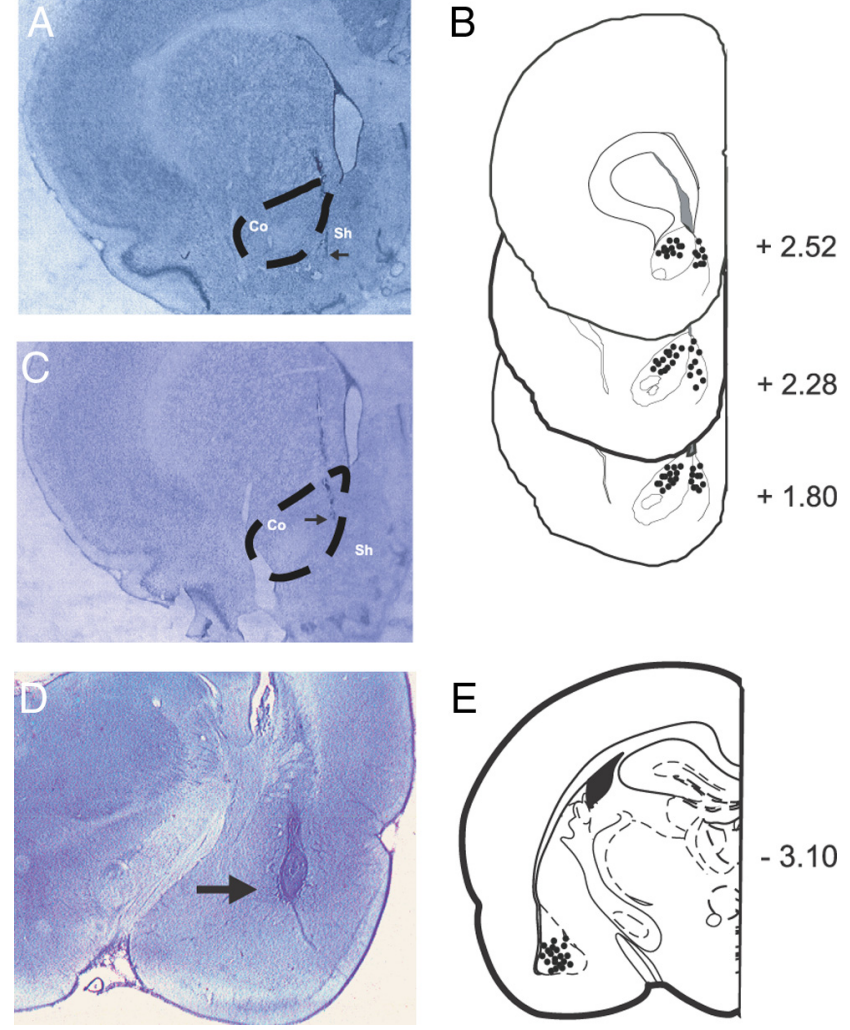

Figure 7. Histological analysis of NAc neuronal recording sites and BLA stimulation sites. $A$, Microphotograph of representative placements of extracellular single-unit recording electrodes within the NAshell and NAcore; $\boldsymbol{B}$, Schematic of coronal sections of the rat brain (Paxinos and Watson, 2005) showing representative placements of the electrodes illustrating various recording sites in the NAc. C, Microphotograph showing representative recording electrode placement in the NAcore. $\boldsymbol{D}$, Microphotograph showing representative intra-BLA microinfusion site. $\boldsymbol{E}$, Schematic representation of unilateral microinfusion sites in the BLA. Co, Core; Sh, shell.

microinfusion sites are presented. In Figure 7A, we present a microphotograph of a representative electrode recording placement in NAshell. In Figure $7 B$, intra-NAshell and intraNAcore recording sites are schematically presented. In Figure $7 C$, we present a microphotograph showing a representative recording site within the NAcore. In Figure 7D, a microphotograph of a representative BLA microinfusion site is presented and group BLA infusion sites are summarized in Figure $7 E$.

Nucleus accumbens neuronal response patterns in the opiate-naive versus opiate-dependent/withdrawn state Comparing NAshell and NAcore neuronal activity patterns in previously opiate-naive versus opiate-dependent and withdrawn 
A
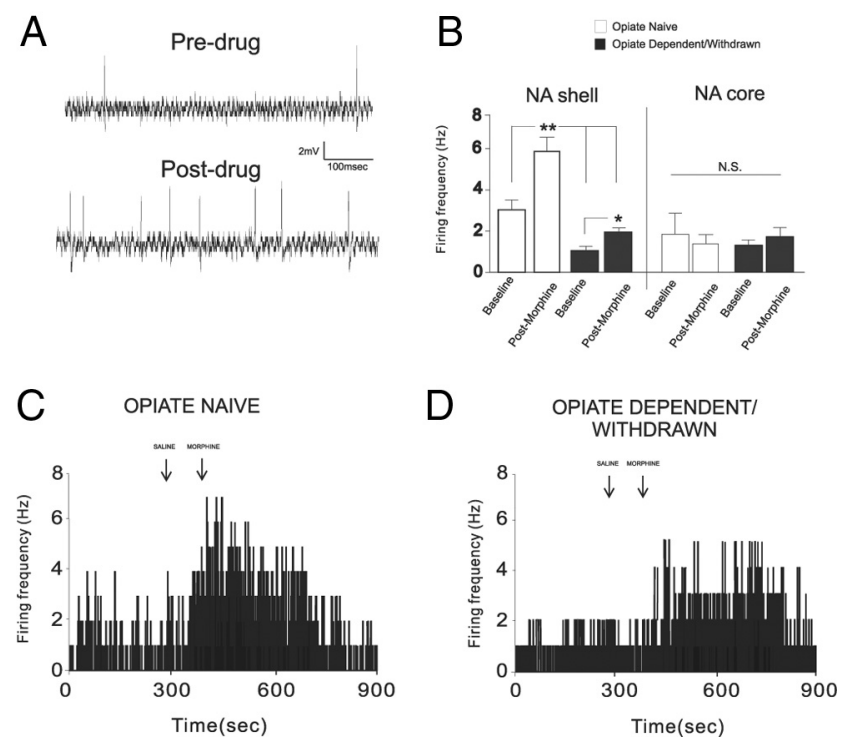

Figure 8. In vivo extracellular single-unit recording in spontaneous putative medium spiny neurons in the NAshell. $A$, Example of a single-unit extracellular recording trace during baseline recording of an NAshell neuron in the opiate-naive group (top) and the same neuron after morphine administration. $\boldsymbol{B}$, Neuronal recording data from NAshell versus NAcore population samples showing effects before versus after morphine administration on spontaneous activity levels in either the opiate-naive or opiate-dependent/withdrawn state. C, Sample NAshell neuronal recording raster showing the effects of morphine administration on spontaneous activity levels in an opiate-naive rat. $\boldsymbol{D}$, Sample NAshell neuronal recording raster showing the effects of morphine administration on spontaneous activity levels in an opiate-dependent/withdrawn rat.

groups revealed significant differences both in terms of spontaneous activity patterns and in terms of responses to morphine administration. Comparing spontaneous neuronal activity patterns during pretreatment versus posttreatment recording epochs across groups (previously opiate-naive vs opiate-dependent/withdrawn) and NAc subregion (NAshell vs NAcore) revealed a significant main effect of group $\left(F_{(1,63)}=10.54, p<\right.$ 0.001 ) and a significant main effect of treatment (baseline vs morphine administration $)\left(F_{(1,63)}=6.7, p<0.01\right)$ on neuronal activity patterns within the NAc (Fig. $8 \mathrm{~B}$ ). Post hoc analyses revealed that for both groups of neurons recorded within the NAshell, spontaneous neuronal activity was significantly increased relative to baseline levels after morphine $(1 \mathrm{mg} / \mathrm{kg}$, i.v. $)$ administration. All NAshell neurons recorded in the opiate-naive state $(100 \%)$ showed relative increases in spontaneous activity after morphine administration. In contrast, $84 \%$ of NAshell neurons recorded in the opiate-dependent/withdrawn state showed relative increases in activity after morphine administration, with $16 \%$ showing no change in activity. Furthermore, NAshell neurons recorded from opiate-dependent and withdrawn rats displayed significantly depressed levels of spontaneous activity relative to the opiate-naive group in terms of both baseline activity levels and activity levels after morphine administration ( $p$ values $<0.05$ ) (Fig. $8 \mathrm{~B}$ ). In contrast, comparing activity levels before and after morphine administration in neurons recorded in NAcore revealed no significant differences between opiate-naive versus opiate-dependent/withdrawn groups either in terms of spontaneous baseline activity levels or in differences between activity levels before and after morphine administration ( $p$ values $>0.05$ ) (Fig. $8 B$ ). NAcore neurons recorded in the opiate-naive state showed mixed responses in activity after morphine administration, with $56 \%$ of neurons showing relative decreases in activity, $43 \%$ showing relative increases, and $1 \%$ showing no change in spontaneous activity. Furthermore, 50\% of NAcore neurons recorded in the opiate-dependent/withdrawn state showed relative increases in activity after morphine administration, with $49 \%$ showing a relative decrease, and $1 \%$ showing no change in activity. In Figure $8 C$, we present a sample rastergram from a NAshell neuron recorded from a previously opiate-naive rat showing levels of activity before and after morphine administration. In Figure $8 D$, we present a sample rastergram recording of an NAshell neuron showing activity levels before and after morphine administration recorded in an opiate-dependent and withdrawn rat.

\section{Intra-BLA dopamine D1 or D2 receptor blockade} differentially blocks NAshell neuronal responses to morphine We next examined whether behaviorally effective doses of intra-BLA SCH23390 $(1 \mu \mathrm{g} / 0.5 \mu \mathrm{l})$ or eticlopride $(1 \mu \mathrm{g} / 0.5 \mu \mathrm{l})$ (Figs. 2, 3) would modulate NAshell neuronal responses to morphine administration $(1 \mathrm{mg} / \mathrm{kg}$, i.v.). NAshell neurons were isolated and recorded during intra-BLA saline, SCH 23390, or eticlopride administration immediately before morphine administration (see Materials and Methods). For NAshell neurons $(n=24)$ recorded in the previously opiate-naive state, comparison of average firing frequencies across recording epochs before versus after morphine administration revealed a significant main effect of group $\left(F_{(2,47)}=11.5, p<0.0001\right)$ and recording epoch $\left(F_{(1,47)}=34.7, p<0.001\right)$ on average neuronal firing activity levels (Fig. $9 A$ ). Post hoc analyses revealed that for both intra-BLA saline and eticlopride groups, NAshell neuronal firing activity was increased significantly relative to baseline after morphine administration ( $p$ values $<0.01$ ). In contrast, for rats receiving intraBLA SCH23390, no significant difference was observed between NAshell neuronal firing frequency before or after morphine administration $(p>0.05)$ (Fig. 9A). We present a sample rastergram demonstrating a typical NAshell neuronal response pattern before and after morphine administration following intra-BLA eticlopride in Figure $9 B$ and a typical response pattern from a rat receiving intra-BLA SCH23390 in Figure $9 C$, both recorded in previously opiate-naive rats.

For NAshell neurons $(n=24)$ recorded in the opiatedependent and withdrawn state, comparison of average firing frequencies across preadministration versus postadministration of morphine recording epochs revealed a significant main effect of group $\left(F_{(2,47)}=8.43, p<0.001\right)$ and recording epoch $\left(F_{(1,47)}=14.44, p<0.001\right)$ on average neuronal firing activity levels (Fig. 9D). Post hoc analyses revealed that for both intra-BLA saline and SCH23390, NAshell neuronal firing activity was increased significantly relative to baseline versus postadministration of morphine ( $p$ values $<0.01$ ). In contrast, for rats receiving intra-BLA eticlopride, no significant difference was observed between NAshell neuronal firing frequency before versus after administration of morphine $(p>0.05)$ (Fig. 9D). We present a sample rastergram demonstrating a typical NAshell neuronal response pattern before versus after administration of morphine following intra-BLA eticlopride in Figure $9 E$ and a typical response pattern from a rat receiving intra-BLA SCH23390 in Figure $9 F$, both recorded in opiate-dependent and withdrawn rats. A summary of these findings is presented as percentage change from baseline levels across the opiate-naive and opiatedependent and withdrawn states following intra-BLA saline, SCH23390, or eticlopride administration in Figure 9G. Thus, doses of intra-BLA SCH23390 or eticlopride that are behaviorally sufficient to block opiate reward processing in the opiate-naive versus opiate-dependent and withdrawn states similarly block NAshell neuronal responses to morphine administration along the same 

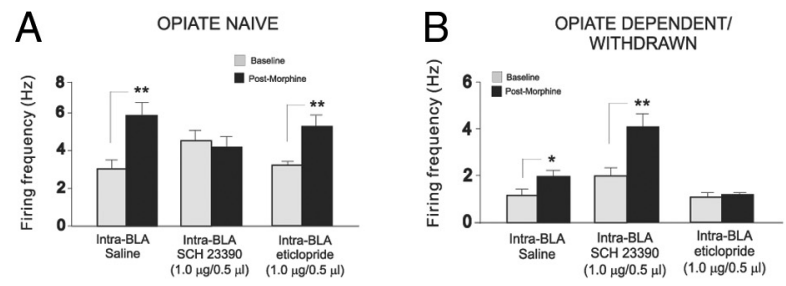

Intra-BLA D1 antagonist (SCH23390,1.0 $\mu \mathrm{g} / 0.5 \mu \mathrm{l})$
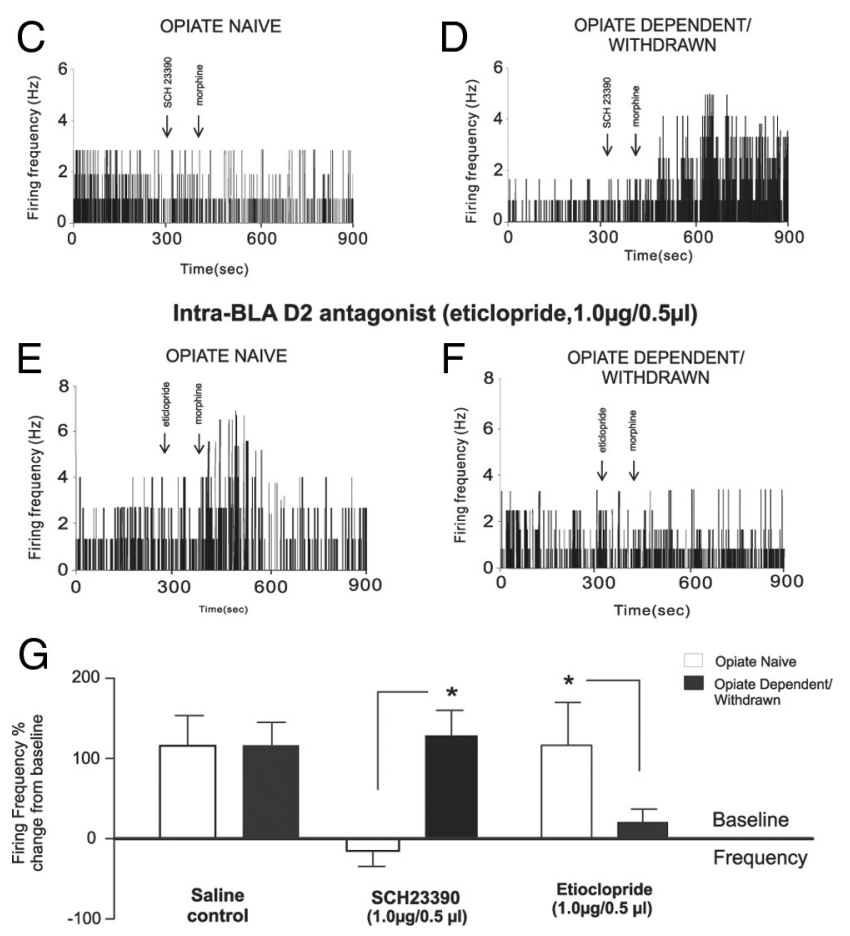

Figure 9. Effects of intra-BLA D1 or D2 receptor blockade on NAshell neuronal response patterns to morphine administration. $A$, Group neuronal recording data from NAshell population samples showing the effects of intra-BLA SCH $23390(1.0 \mu \mathrm{g} / 0.5 \mu \mathrm{ll})$ on neuronal responses to morphine $(1.0 \mathrm{mg} / \mathrm{kg}$, i.v.) administration. Whereas intra-BLA D1 receptor blockade blocks excitatory responses to morphine administration in opiate-naive rats, the same treatment does not block NAshell neuronal responses to morphine in rats recorded in the opiatedependent/withdrawn state. $\boldsymbol{B}$, Neuronal recording data from NAshell population samples showing the effects of intra-BLA eticlopride $(1.0 \mu \mathrm{g} / 0.5 \mu \mathrm{l})$ on neuronal activity following morphine $(1.0 \mathrm{mg} / \mathrm{kg}$, i.v.) administration. Whereas intra-BLA D2 receptor blockade has no effects on excitatory NAshell neuronal responses to morphine in rats recorded in the opiatenaive state, the same treatment completely blocked NAshell neuronal responses to morphine in rats recorded in the opiate-dependent/withdrawn state. C, Sample NAshell neuronal recording rastergram showing the effects of intra-BLA SCH 23390 on neuronal activity after morphine administration in an opiate-naive rat. $\boldsymbol{D}$, Sample NAshell neuronal recording rastergram showing the effects of intra-BLA SCH 23390 on neuronal activity after morphine administration in an opiatedependent/withdrawn rat. $\boldsymbol{E}$, Sample NAshell neuronal recording rastergram showing the effects of intra-BLA eticlopride on neuronal activity after morphine administration in an opiate-naive rat. $\boldsymbol{F}$, Sample NAshell neuronal recording rastergram showing the effects of intra-BLA SCH eticlopride on neuronal responding to morphine administration in an opiate-dependent/withdrawn rat. G, Summary of NAshell neuronal group responses to morphine administration expressed as percentage change from baseline across saline control groups, intra-BLA SCH 23390 experimental groups, and intra-BLA eticlopride experimental groups.

functional boundary for D1-like versus D2-like receptor transmission within the BLA.

Intra-BLA dopamine D1-like or D2-like receptor blockade has no effect on NAcore neuronal responses to morphine We further examined whether behaviorally effective doses of intra-BLA SCH23390 $(1 \mu \mathrm{g} / 0.5 \mu \mathrm{l})$ or eticlopride $(1 \mu \mathrm{g} / 0.5 \mu \mathrm{l})$ (Figs. 2, 3) would modulate NAcore neuronal responses to mor- phine administration ( $1 \mathrm{mg} / \mathrm{kg}$, i.v.). Using our previously described procedure, NAcore neurons were simultaneously isolated and recorded along with NAshell neurons (see Materials and Methods) during intra-BLA saline, SCH 23390, or eticlopride administration immediately before morphine administration. For NAcore neurons $(n=24)$ recorded in the previously opiatenaive state, comparison of average firing frequencies across recording epochs before versus after morphine administration revealed no significant main effects of group $\left(F_{(2,47)}=0.14, p>\right.$ $0.05)$ or recording epoch $\left(F_{(1,47)}=0.2, p>0.05\right)$ on average neuronal firing activity levels (Fig. 10A). Post hoc analyses revealed no differences between baseline versus after morphine administration recording epochs for either intra-BLA saline $(n=$ $8)$, eticlopride $(n=8)$, or SCH23390 $(n=8)$ groups ( $p$ values $>0.05)$. For NAcore neurons $(n=24)$ recorded in the opiatedependent and withdrawn state, comparison of average firing frequencies across recording epochs before versus after morphine administration revealed no significant effect of group $\left(F_{(2,47)}=\right.$ $0.27, p>0.05)$ or recording epoch $\left(F_{(1,47)}=0.11, p>0.05\right)$ on average neuronal firing activity levels (Fig. $10 \mathrm{~B}$ ). Post hoc analyses revealed no differences between baseline versus after morphine administration recording epochs for either intra-BLA saline $(n=$ $8)$, eticlopride $(n=8)$, or SCH23390 $(n=8)$ groups ( $p$ values $>0.05$ ) in NAcore neurons recorded in the opiate-dependent and withdrawn state. In Figure 10C, group data for NAcore neuronal recordings are presented as percentage change from baseline following morphine administration for groups receiving intra-BLA saline, SCH23390 $(1 \mu \mathrm{g} / 0.5 \mu \mathrm{l})$, or eticlopride $(1 \mu \mathrm{g} / 0.5 \mu \mathrm{l})$ in either the opiate-naive or opiate-dependent and withdrawn states. Thus, in contrast to neurons of the NAshell, neurons in the NAcore failed to show responsiveness to morphine administration regardless of opiate exposure state. Furthermore, intra-BLA D1 or D2 receptor blockade had no influence on these neuronal activity patterns.

\section{Discussion}

Emerging evidence implicates the importance of the BLA $\rightarrow$ NAc circuit in the opiate addiction process (Frenois et al., 2005; Upadhyay et al., 2010; Xie et al., 2011). Opiate dependence and withdrawal are associated with structural and functional abnormalities in the amygdala of abstinent opiate-dependent patients and disturbed functional connectivity between the amygdala and associated pathways, including the PFC and NAc (Upadhyay et al., 2010). Previous reports demonstrate an important role for intra-BLA DA transmission during the processing of drug-related reward learning and relapse-related phenomena. Berglind et al. (2006) reported that intra-BLA D1 receptor blockade prevented conditioned reinstatement of responding for cocaine using an intravenous self-administration procedure. Blockade of D1/D2 receptor transmission within the BLA, but not central nucleus of the amygdala, has been reported to block the expression of CPP for ethanol (Gremel and Cunningham, 2009). Functionally, D1 and D2 receptor activation can modulate neuronal activity patterns within the BLA by direct activation of interneuron populations or via direct actions on projection neuron populations (Rosenkranz and Grace, 2002; Kröner et al., 2005). Given that VTA $\rightarrow$ BLA DAergic projections modulate synaptic associative plasticity mechanisms within the BLA (Bissière et al., 2003) and subsequent reports demonstrating that opiates preferentially activate VTA DAergic projections to the BLA (Ford et al., 2006), it is not surprising that intra-BLA DA transmission would modulate opiaterelated reward signaling. However, how might opiate exposure and withdrawal states regulate intra-BLA D1 versus D2 func- 


\section{A PREVIOUSLY OPIATE NAIVE}

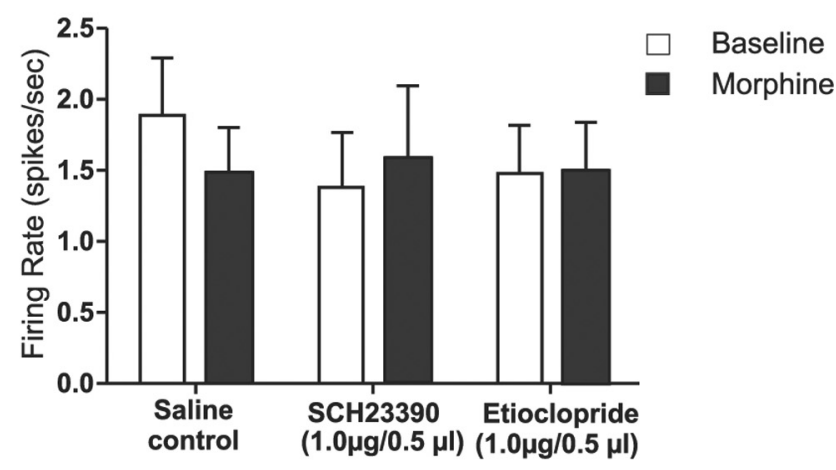

B OPIATE DEPENDENT/WITHDRAWN
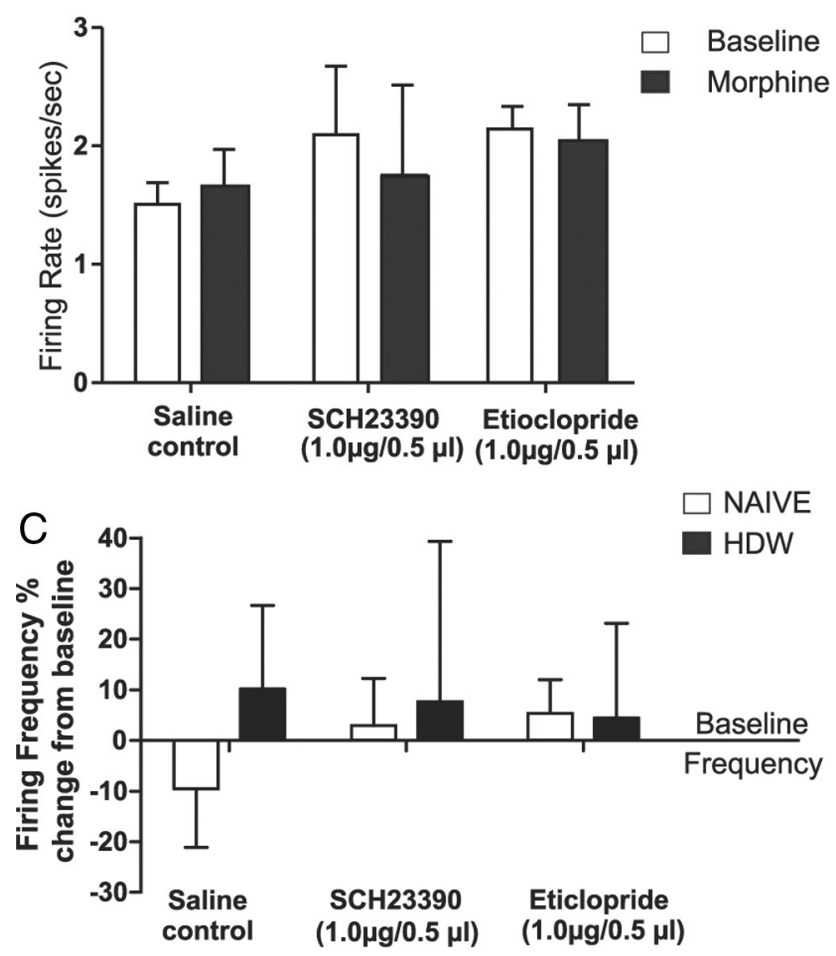

Figure 10. Effects of intra-BLA D1 or D2 receptor blockade on NAcore neuronal response patterns to morphine administration. $\boldsymbol{A}$, Neuronal recording data from NAcore population samples in opiate-naive rats, comparing the effects of intra-BLA saline, $\mathrm{SCH} 23390(1.0 \mu \mathrm{g} / 0.5 \mu \mathrm{l})$, or eticlopride $(1.0 \mu \mathrm{g} / 0.5 \mu \mathrm{l}$ ) on neuronal responses to morphine $(1.0 \mathrm{mg} / \mathrm{kg}$, i.v.) administration. No significant differences were observed across any groups before versus after morphine administration. $\boldsymbol{B}$, Neuronal recording data from NAcore population samples in opiate-dependent/withdrawn rats, comparing the effects of intra-BLA saline, SCH $23390(1.0 \mu \mathrm{g} / 0.5 \mu \mathrm{l})$, or eticlopride $(1.0 \mu \mathrm{g} / 0.5 \mu \mathrm{l})$ on neuronal responses to morphine $(1.0 \mathrm{mg} / \mathrm{kg}$, i.v. $)$ administration. Similar to the opiate-naive samples, no significant differences were observed across any groups before versus after morphine administration. C, Summary of NAcore neuronal group responses to morphine administration expressed as percentage change from baseline across saline control groups, intra-BLA SCH 23390 experimental groups, and intra-BLA eticlopride experimental groups.

tional transmission during the encoding of opiate-related reward information?

Previous evidence suggests a switch in the functional roles of D1-like versus D2-like receptor transmission within the BLANAc circuitry during distinct phases of opiate exposure. Thus, Bhargava and Gulati (1990) reported that chronic opiate exposure caused significant decreases in D1 receptor binding levels within the amygdala during opiate withdrawal. Such a decrease in
intra-BLA D1 receptor function is consistent with our observations that D1 receptor blockade failed to modulate opiate reward processing either behaviorally or in terms of NAc neuronal responses to morphine in the opiate-dependent/withdrawn state. Although no extant evidence demonstrates a specific intra-BLA upregulation of D2 receptors following chronic opiate exposure, previous evidence suggests a D2-like receptor sensitivity shift in the opiate withdrawn state demonstrated by increased sensitivity to D2 receptor agonists in terms of locomotor and stereotypy measures (Druhan et al., 2000). Our results demonstrate a shift within the BLA between a D1-like to a D2-like receptor substrate following chronic opiate exposure and withdrawal. This shift may result as a default process following D1-like receptor desensitization after chronic opiate exposure within the BLA (Bhargava and Gulati, 1990). Thus, one possibility for our observed desensitization to the effects of intra-BLA D1 receptor blockade during the opiate-dependent and withdrawn state may be the result of altered VTA-BLA DA firing activity, resulting in intra-BLA D1 receptors' internalization on GABAergic interneurons, which theoretically would render pharmacological manipulations of BLA D1 receptors ineffective in blocking the encoding of opiate reward memory, as we observed in the opiate-naive state. Simultaneously, such a functional shift between D1 and D2 receptors across opiate exposure states may explain why D2 receptor substrates become functionally necessary during the opiate-dependent/withdrawn state. A further explanation may come from anatomical studies demonstrating relatively greater concentrations of D1 versus D2 receptors in the BLA (Weiner et al., 1991; Missale et al., 1998), suggesting preferential sensitivity to D1 receptor manipulations, at least in the opiate-naive condition.

One alternative explanation may relate to anatomical distributions of intra-BLA D2 versus D1 receptor substrates. For example, Pinto and Sesack (2008) demonstrated a preferential localization of intra-BLA D2 receptors on presynaptic terminals originating from the PFC and D1 receptors localized predominantly postsynaptic to PFC terminals. Given the importance of the PFC in terms of reactivity to opiate-related associative cues (Bishop et al., 2011), one possibility is that in the opiate-dependent/withdrawn state, opiate-related associative cues preferentially activate $\mathrm{PFC} \rightarrow \mathrm{BLA}$ projections, which in turn would be more sensitive to $\mathrm{D} 2$-like receptor blockade within the BLA given the preferential localization of these receptors on descending PFC inputs to BLA neuronal populations. Interestingly, we found that the switch between intra-BLA D1 and D2 transmission in terms of opiate reward processing was transient. Indeed, once recovery from opiate exposure had occurred, the functional state of BLA D1 versus D2 transmission reverted to the opiate-naive state. This demonstrates that at least within the BLA, a state of opiate withdrawal is a prerequisite for the switch to a D2-like receptor substrate for opiate reward processing. This may be consistent with the suggestion that opiate dependence and withdrawal may enlist greater top-down cortical involvement from the PFC, possibly related to the stronger salience associated with drug cues during a state of withdrawal. In contrast, once the dependence/withdrawal state has been removed, the involvement of PFC input to BLA-related opiate reward processing may recede. Although future studies are required to address these issues, the current findings demonstrate a strong dissociation between D1-like and D2-like functional transmission within the BLA as a direct function of opiate exposure state, both in terms of controlling the acquisition of opiate-related reward memory and in controlling NAshell neuronal responses to morphine administration. 
Intra-BLA dopamine transmission modulates neuronal responses to opiates in the nucleus accumbens shell

Beyond playing a critical role in opiate reward-related behaviors, the NAc has functionally important connections with the BLA. For example, BLA stimulation excites neurons of the NAc through GLUTergic projections specifically via NMDA and DA D1 receptor transmission (Floresco et al., 1998, 2001). Blockade of intra-BLA D1 receptor transmission blocks stress-induced release of DA directly within the NAc (Stevenson and Gratton, 2003 ), suggesting that BLA $\rightarrow$ NAc projections modulate DAmediated neuronal responses to emotionally salient events. Although transmission through BLA DA receptors can modulate neuronal activity and intra-NAc DA release, the effects of intraBLA DA receptor modulation on NAc neuronal responses to morphine have not been examined previously. In terms of opiate reward processing, DA transmission within the NAc is critical for opiate reward learning in the opiate-naive state, but not in the opiate-dependent/withdrawn state (Laviolette et al., 2002). However, little is known regarding how chronic opiate exposure changes BLA-mediated modulation of opiate reward memory. We report that the same behaviorally effective doses of intra-BLA D1 or D2 receptor antagonists that blocked opiate reward memory acquisition in either the opiate-naive or opiate-dependent/ withdrawn states, respectively, produced concomitant blockade of NAshell-specific neuronal responses to morphine. Our in vivo neuronal recording experiments revealed a profound reduction in baseline activity patterns within NAshell (but not NAcore) neuronal populations in the opiate-withdrawn state. This is consistent with recent evidence demonstrating that opiate exposure and withdrawal are associated with marked hypofunction of DA transmission (Diana et al., 1995). Interestingly, the withdrawal from chronic morphine exposure is correlated with decreased spine density specifically within NAshell neuronal synapses associated with mesolimbic DA target convergence. These results are consistent with our findings showing selective attenuation of spontaneous NAshell, but not NAcore, neuronal activity. Furthermore, a postsynaptic reduction in NAshell spine number might reduce total membrane surface area, thus decreasing membrane resistance and leading to attenuated excitability and spontaneous activity, consistent with our in vivo recordings. Nevertheless, despite decreased spontaneous neuronal activity, NAshell neurons still showed significantly increased activity in response to opiate administration, an effect that was specifically blocked by D2 receptor antagonism within the BLA in the opiatewithdrawn state.

Opiates can produce either excitation or inhibition on the spontaneous activity levels of NAc neurons recorded in vivo (Hakan and Henriksen, 1987, 1989). As noted previously, the BLA sends functionally significant GLUTergic projections to neurons within the NAc, which produces excitatory responses on NAc neuronal populations (Floresco et al., 2001). While previous evidence demonstrates the importance of NAc DA transmission for mediating opiate reward signaling, specifically within the opiatedependent and withdrawn state (Nader and van der Kooy, 1997; Laviolette et al., 2002), anatomical evidence has demonstrated that DA neurons within the VTA that are indirectly activated via $\mu$ opiate-mediated inhibition of VTA GABAergic neurons preferentially project to the BLA relative to the NAc (Ford et al., 2006). Given this evidence and our present findings that intra-BLA DA D1/D2 receptor modulation was able to control opiate reward processing originating directly from the VTA, we propose that associative, opiate-related reward information may first access the BLA from the VTA. Once associative opiate reward memories are formed within BLA neuronal circuits, this information may then be transmitted via a BLA $\rightarrow$ NAshell pathway for the behavioral expression of opiate-related reward memory.

\section{Conclusions}

We report a novel opiate reward switching mechanism within the BLA that switches from a D1-like receptor substrate to a D2-like receptor substrate during the transition from the opiate-naive to the opiate-dependent and withdrawn state. This switch is regulated by downstream PKA/cAMP signaling and is functionally reversible once recovery from opiate exposure has taken place. Our findings further demonstrate a novel functional pathway between intra-BLA DA transmission and NAshell neuronal response patterns to opiate administration and provide further evidence for the importance of amygdala-striatal connections during the processing of opiate-related reward memories.

\section{References}

Ambroggi F, Ishikawa A, Fields HL, Nicola SM (2008) Basolateral amygdala neurons facilitate reward-seeking behavior by exciting nucleus accumbens neurons. Neuron 59:648-661.

Baxter MG, Murray EA (2002) The amygdala and reward. Nat Rev Neurosci 3:563-573.

Berglind WJ, Case JM, Parker MP, Fuchs RA, See RE (2006) Dopamine D1 or D2 receptor antagonism within the basolateral amygdala differentially alters the acquisition of cocaine-cue associations necessary for cueinduced reinstatement of cocaine-seeking. Neurosci 137:699-706.

Bhargava HN, Gulati A (1990) Modification of brain and spinal cord dopamine D1 receptors labeled with [3H]SCH 23390 after morphine withdrawal from tolerant and physically dependent rats. J Pharmacol Exp Ther 252:901-907.

Bishop SF, Lauzon NM, Bechard M, Gholizadeh S, Laviolette SR (2011) NMDA receptor hypofunction in the prelimbic cortex increases sensitivity to the rewarding properties of opiates via dopaminergic and amygdalar substrates. Cereb Cortex 21:61-80.

Bissière S, Humeau Y, Lüthi A (2003) Dopamine gates LTP induction in lateral amygdala by suppressing feedforward inhibition. Nat Neurosci 6:587-592.

Diana M, Pistis M, Muntoni A, Gessa G (1995) Profound decrease of mesolimbic dopaminergic neuronal activity in morphine withdrawn rats. J Pharmacol Exp Ther 272:781-785.

Druhan JP, Walters CL, Aston-Jones G (2000) Behavioral activation induced by D2-like receptor stimulation during opiate withdrawal. J Pharmacol Exp Ther 294:531-538.

Dwivedi Y, Rizavi HS, Pandey GN (2002) Differential effects of haloperidol and clozapine on $[3 \mathrm{H}]$ cAMP binding, protein kinase A (PKA) activity, and mRNA and protein expression of selective regulatory and catalytic subunit isoforms of PKA in rat brain. J Pharmacol Exp Ther 301:197-209.

Floresco SB, Yang CR, Phillips AG, Blaha CD (1998) Basolateral amygdala stimulation evokes glutamate receptor-dependent dopamine efflux in the nucleus accumbens of the anaesthetized rat. Eur J Neurosci 10:1241-1251.

Floresco SB, Blaha CD, Yang CR, Phillips AG (2001) Dopamine D1 and NMDA receptors mediate potentiation of basolateral amygdala-evoked firing in nucleus accumbens neurons. J Neurosci 21:6370-6376.

Ford CP, Mark GP, Williams JT (2006) Properties and opioid inhibition of mesolimbic dopamine neurons vary according to target location. J Neurosci 26:2788-2797.

Frenois F, Stinus L, Di Blasi F, Cador M, Le Moine C (2005) A specific limbic circuit underlies opiate withdrawal memories. J Neurosci 25:1366-1374.

Fuchs RA, See RE (2002) Basolateral amygdala inactivation abolishes conditioned stimulus and heroin-induced reinstatement of extinguished heroin seeking behavior in rats. Psychopharmacology 160:425-433.

Gremel CM, Cunningham CL (2009) Involvement of amygdala dopamine and nucleus accumbens NMDA receptors in ethanol-seeking behavior in mice. Neuropsychopharmacology 34:1443-1453.

Hakan RL, Henriksen SJ (1987) Systemic opiate administration has heterogeneous effects on activity recorded from nucleus accumbens neurons in vivo. Neurosci Lett 83:307-312.

Hakan RL, Henriksen SJ (1989) Opiate influences on nucleus accumbens 
neuronal electrophysiology: dopamine and non-dopamine mechanisms. J Neurosci 9:3538-3546.

Kröner SK, Rosenkranz JA, Grace AA, Barrionuevo G (2005) Dopamine modulates excitability of basolateral amygdala neurons in vitro. J Neurophysiol 93:1598-1610.

Laviolette SR, van der Kooy D (2003) Blockade of mesolimbic dopamine transmission dramatically increases sensitivity to the rewarding effects of nicotine in the ventral tegmental area. Mol Psychiatry 8:50-59.

Laviolette SR, Nader K, van der Kooy D (2002) Motivational state determines the functional role of the mesolimbic dopamine system in the mediation of opiate reward processes. Behav Brain Res 129:17-29.

Laviolette SR, Gallegos RA, Henriksen SJ, van der Kooy D (2004) Opiate state controls bi-directional reward signaling via $\mathrm{GABA}_{\mathrm{A}}$ receptors in the ventral tegmental area. Nat Neurosci 7:160-169.

McDonald AJ (1991a) Organization of amygdaloid projections to the prefrontal cortex and associated striatum in the rat. Neuroscience 44:1-14.

McDonald AJ (1991b) Topographical organization of amygdaloid projections to the caudatoputamen, nucleus accumbens, and related striatal-like areas of the rat brain. Neurosocience 44:15-33.

Missale C, Nash SR, Robinson SW, Jaber RM, Caron MG (1998) Dopamine receptors: from structure to function. Physiol Rev 78:189-225.

Nader K, van der Kooy (1997) Deprivation state switches the neurobiological substrates mediating opiate reward in the ventral tegmental area. J Neurosci 17:383-390.

Olmstead MC, Franklin KB (1997) The development of a conditioned place preference to morphine: effects of microinjections into various CNS sites. Behav Neurosci 111:1324-1334.
Paxinos G, Watson C (2005) The rat brain in stereotaxic coordinates. Amsterdam: Elsevier Academic.

Pinto A, Sesack SR (2008) Ultrastructural analysis of prefrontal cortical inputs to the rat amygdala: spatial relationships to presumed dopamine axons and D1 and D2 receptors. Brain Struct Funct 213:159-175.

Rosenkranz JA, Grace AA (2002) Cellular mechanisms of infralimbic and prelimbic prefrontal cortical inhibition and dopaminergic modulation of basolateral amygdala neurons in vivo. J Neurosci 22:324-337.

Senogles SE, Amlaiky N, Berger JG, Caron MG (1988) Biochemical properties of D1 and D2 dopamine receptors. Adv Exp Med Biol 235:33-41.

Stevenson CW, Gratton A (2003) Basolateral amygdala modulation of the nucleus accumbens dopamine response to stress: role of the medial prefrontal cortex. Eur J Neurosci 17:1287-1295.

Upadhyay J, Maleki N, Potter J, Elman I, Rudrauf D, Knudsen J, Wallin D, Pendse G, McDonald L, Griffin M, Anderson J, Nutile L, Renshaw P, Weiss R, Becerra L, Borsook D (2010) Alterations in brain structure and functional connectivity in prescription opioid-dependent patients. Brain 133:2098-2114

Weiner DM, Levey AI, Sunahara RK, Niznik HB, O’Dowd BF, Seeman P, Brann MR (1991) D1 and D2 dopamine receptor mRNA in rat brain. Proc Natl Acad Sci U S A 88:1859-1863.

Xie C, Li SJ, Shao Y, Fu L, Goveas J, Ye E, Li W, Cohen AD, Chen G, Zhang Z, Yang Z (2011) Identification of hyperactive intrinsic amygdala network connectivity associated with impulsivity in abstinent heroin addicts. Behav Brain Res 216:639-646. 